\title{
CONCEPÇÕES SOBRE A MATEMÁTICA E PRÁTICAS AVALIATIVAS: AS POSSÍVEIS RELAÇÕES
}

\author{
HELENA NORONHA CURY ${ }^{*}$
}

Um dos assuntos mais evidenciados, nos últimos congressos de Educação Matemática, é a investigaçăo sobre as concepções dos professores à respeito da Matemática e de seu ensino. Vários autores, discorrendo sobre as visð̄es filosóficas da Matemática, têm pesquisado as possfveis relações entre essas concepções e as práticas pedagógicas.

Blaire (1981) identifica quatro correntes filosóficas em Matemática: o logicismo, o formalismo, o intuicionismo ${ }^{1} \mathrm{e}$ um quarto movimento que ele chama de "hipotético" e que estaria relacionado às explicações sobre os usos e limitaçōes da Matemática. Essa última visão, segundo ele, ter-se-ia desenvolvido, de certa forma, através dos trabalhos de Lakatos.

Mesmo advertindo o leitor sobre a impossibilidade de associar, diretamente, uma tendência pedagógica a cada visåo filosófica, Blaire

"Professom da Poutiffeis Universidufe Crathica da Rio Grande do Sul (PUC-RS)

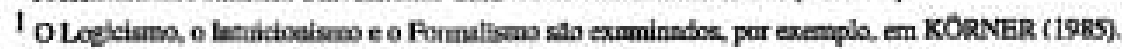


apresenta quatro possíveis perspectivas para o ensino da Matemática: como arte, como jogo, como ciência natural e como atividade tecnicamente orientada. Para discorrer sobre cada uma das tendências, o autor vale-se de um fictício professor de Matemática que teria recebido, em sua formaçāo, as influências de todas essas visōes sobre o ensino de Matemática e que, ao iniciar sua carreira, adota cada uma das perspectivas com as diferentes turmas com as quais trabalha.

Ao ensinar Matemática em forma de arte, o jovem professor procura mostrar aos alunos a beleza dessa disciplina e, trabalhando com Geometria, procura levar os estudantes a admirarem a elegância e o rigor das demonstraçöes. Tais idéias sugerem que Blaire associa o ensino em forma de arte à visão logicista: Russell também se encantava com a "fria beleza" da Matemática e procurava estabelecer demonstrações matemáticas rigorosas, reduzindo-as à Lógica.

Em outra turma, o professor, imaginado por Blaire, vai ensinar Matemática como um jogo, utilizando Batalha Naval ou xadrez como recursos para motivar os alunos e incutir neles a idéia de que, assim como os jogos, a Matemática tem regras rígidas que devem ser seguidas por quem quer ganhar o jogo. Blaire parece estar fazendo uma relação entre essa forma de ensinar e a visão formalista da Matemática.

A visāo hipotética, ou seja, a perspectiva Lakatosiana de formular conjeturas e testá-las, é evidenciada quando o jovem professor vai dar uma aula sobre a fórmula de $E_{\text {ule }}{ }^{2}$ e apela para o método de descoberta segundo o qual as hipóteses săo testadas e modificadas quando necessário, assim como faz o cientista ao descobrir uma lei nas ciências naturais.

Em uma última perspectiva, o professor vai trabalhar com os alunos sobre um problema da vida real, para o qual procurarăo as soluçōes, a partir da criaçäo de um modelo matemático que simule o problema real e permita discutir as possibilidades de solução c a aplicabilidade tecnológica do modelo.

As idéias de Blaire sugerem, em primeiro lugar, que os professores possam ter uma postura tipo camaleão, mimetizando-se segundo as necessidades da turma para a qual lecionarăo. Năo

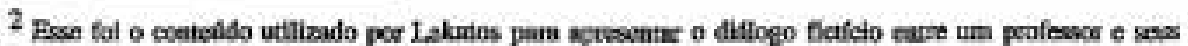
aluoses en sua magistral oben Pruvas e Refintaçöes.
} 
acreditamos que haja uma correspondência tão estreita entre uma visão formalista, por exemplo, e a forma de ensinar que a reproduza. Se o professor segue as concepçб̃es formalistas e tenta ensinar segundo esse modelo, sua preocupaçăo deveria ser com a apresentaçăo dos conteúdos em uma seqüência do tipo definição-axioma-teorema.

Ao final do artigo, Blaire parece dar-se conta da rigidez de suas associações entre visōes filosóficas e posturas pedagogicas, pois comenta:

"... a popularidade, nos últimos quinze anos, do ensino de Matemática como um jogo, näo significa que todos os que defendem a orientaçäo de 'usar jogos' sejam formalistas. Enquanto alguns, que seguem esta orientação, são formalistas, outros simplesmente crêem que tal perspectiva facilita o desempenho de seus alunos nas verificações." (BLAIRE, 1981, p.152)

Tais palavras, portanto, já sugerem uma relação entre a visão formalista e a avaliação: vista como um conjunto de regras, leva o aluno a reproduzir essas regras de forma rigida, sem falhas, sem desvios. Se esse é o objetivo do professor ao elaborar o instrumento de avaliação, então o aluno terá um desempenho favorável. Portanto, o que está em pauta não é, apenas, a correspondência entre uma forma de conceber a Matemática e uma forma de ensiná-la; é, também, a idéia da avaliaçăo que está ligada a cada concepção.

Lerman (1983) não aceita as idéias de Blaire, porque considera que as conexōes entre as concepçōes filosóficas e os estilos de ensinar são muito mais fortes do que Blaire sugere, apesar de menos detectáveis no trabalho diário do professor. Lerman segue a proposta de Lakatos e agrupa as visōes filosóficas da Matemática sob duas perspectivas: a Euclideana c a quase-empiricista. Cada uma delas subsidia uma determinada metodologia determinante de dois estilos opostos de ensino de Matemática: centrado no conhecimento ou centrado na resolução de problemas.

Se o ensino é centrado no conteúdo, o professor enfatiza a beleza das demonstraçöes, exige a prova de todos os resultados, justifica o uso de determinados algoritmos, enfim, transmite um conhecimento estável, hierarquicamente estruturado, em que cada conteúdo depende dos anteriores. 
De outra parte, se o ensino é centrado na resolução de problemas, o professor näo impõe a solução. Ela ć buscada, em conjunto, pelo grupo de alunos que testa hipóteses e as refuta. $\mathrm{E}$ o conhecimento desenvolve-se a partir das correçōes, em um constante refinamento.

A classificação das visões filosóficas da Matemática em duas correntes que se opōem também é proposta por Ernest (1985, 1991b). Entre as concepçōes absolutistas, que vêem a Matemática como o domínio do conhecimento incontestável, Ernest aponta o platonismo? o logicismo, o intuicionismo e o formalismo. No lado oposto, situa-se a perspectiva falibilista - sustentada pelas idéias de Lakatos e, mais recentemente, por Davis, Hersh e Tymockzo -, segundo a qual a Matemática é uma atividade humana, imperfeita e sujeita a erros, que cresce através das críticas e correçốes feitas pela comunidade matemática.

Em Ernest (1989, 1991a), o autor sugere as possíveis relaçōes entre as concepções filosóficas e as posturas pedagógicas, sendo que a oposição entre as visőes absolutista e falibilista é apresentada como a contraposição respectiva entre o ensino de Matemática como produto e como processo.

Se a Matemática é vista como o produto do saber acumulado pelas geraçōes, além de posturas como a busca de verdade absoluta, a ênfase nas demonstraçoúes de teoremas e a prática de exercícios rotineiros, Ernest aponta, na avaliaçăo das verificaçōes realizadas pelos alunos, a estigmatização dos erros cometidos. De outra parte, se a Matemática é vista como processo, além do engajamento dos alunos na busca de soluções para problemas năo rotineiros, Ernest salienta a aceitação dos erros como passo necessário no trabalho dos alunos. Eles lançam hipóteses e testam-nas sem se preocuparem em usar apenas o permitido pelo professor, aventurando-se em conjeturas próprias.

Davis (1988) classifica as filosofias da Matemática em privadas e públicas, utilizando termos que teriam sido sugeridos por Tymockzo (1986). O platonismo, o logicismo, o intuicionismo e o formalismo seriam filosofias privadas, pois cada matemático, em qualquer uma dessas escolas, trabalha isolado do resto da humanidade, descobrindo

\footnotetext{
${ }^{3}$ O platweiseno ed discutido, por exerrplo, em ERNEST (1991 b).
} 
(ou criando, de acordo com a concepçäo filosófica assumida) as precisas e eternas relaçб̌es entre os entes matemáticos, que são entes da razäo. Segundo Davis, quando o ensino de Matemática se baseia nesse tipo de filosofia, em geral, segue o padrão formalista do tipo: faz assim, aplica tal definiçāo, usa tal algoritmo.

As filosofias públicas entendem que o conhecimento matemático nåo é criado individualmente, mas é parte do conhecimento de uma comunidade - os matemáticos, os pesquisadores, os professores, os alunos de Matemática - que pratica uma determinada atividade e cujas criaçōes são discutidas, corrigidas, retomadas através das publicações dos membros da comunidade, de suas palestras, de suas aulas. A comunidade matemática, inserida em uma determinada sociedade e cultura, vai refletir sobre as necessidades dessa sociedade e, entāo, trabalhará sobre os conteúdos matemáticos utilizados por e para essa sociedade.

A matematizaçāo de quase todas as áreas do conhecimento, a (talvez) excessiva utilizaçāo da informática nas ciências sociais e biológicas, faz com que o homem esteja cada vez mais à mercê da "perversão matemática", expressão usada por Upinsky (1989). Visto que somos "beneficiários e vítimas, toda a matematizaçāo deveria ser aberta em fórum público, onde as idéias são debatidas. Esses debates deveriam começar na escola secundária."(DAVIS, 1988, p.144).

Portanto, a filosofia pública da Matemática, que vem tomando forma a partir das idéias de Lakatos e sendo defendida por matemáticos como Davis, Hersh, Tymockzo e Ernest, entre outros, embasaria uma nova forma de ensinar, centrada nos problemas da sociedade e na emergência de soluçōes para esses problemas. As soluções seriam criadas pelos membros dessa sociedade, estimulados, desde os primeiros anos de escolaridade, a propor soluçōes, levantar hipóteses, testá-las, criticá-las.

Apesar das considerações dos autores acima citados, não acreditamos ser possível fazer uma associaçăo estreita entre uma visão filosofica da Matemática e uma tendência pedagógica que the seja correspondente. Em geral, näo existem posturas do professor de Matemática, características de uma escola de pensamento matemático. Um determinado professor, com uma determinada concepção de Matemática, pode agir de maneira diferente em relaçăo a turmas diversas, devido às influências dos alunos, da Instituição, dos colegas ou da realidade sócio-econômica de cada escola. Da mesma forma, 
professores com concepçōes filosóficas opostas podem, pelo mesmo tipo de influencias, realizar trabalhos muito semelhantes em uma determinada turma e escola. Assim, parece-nos que devemos exarninar as possíveis relações entre as concepções e as práticas, tentando entender, também, como as circunstâncias modelam essas relaçőes.

Os autores que dividem as visőes filosoficas em categorias opostas e as relacionam a determinadas práticas pedagógicas, enunciam consideraçōes gerais sobre o processo de ensinoaprendizagem de Matemática, sem se deterem em aspectos específicos, como a avaliaçảo da aprendizagem. Iremos, agora, tecer consideraçōes sobre certas práticas avaliativas em Matemática, especialmente em nível de $3^{\circ}$ grau, para tentar estabelecer suas possf́veis relações com as concepçōes filosóficas.

Dependendo da disciplina, do curso no qual ela é lecionada e das normas da Universidade, a savaliação da aprendizagem em Matemática é feita, em geral, através da aplicação de provas escritas e de trabalhos (individuais ou $\mathrm{cm}$ grupo) realizados durante o semestre letivo. Reportando-nos à elaboração das provas, surgem as primeiras dúvidas: que conteúdos devern ser abordados? que tipos de questóes serāo elaboradas para a avaliação do conhecimento de determinado conteúdo? quais os critérios para aceitar uma resoluçăo como certa? A resposta a cada uma dessas indagaçōes já permitiria, possivelmente, detectar inúmeros problemas no processo.

A elaboração da prova e sua aplicação já săo antecedidas, na maior parte das vezes, por certas atitudes do professor e dos alunos. Em alguns casos, o professor intimida os estudantes, incitando-os a estudar, pois "a prova năo será fácil"; em outras ocasiốes, com receio de que os alunos tenham um mau desempenho em questōes que ele considera dificeis, o professor dá dicas sobre a resolução ou pistas sobre os contcúdos que serão abordados.

Evidentemente, uma ou outra dessas atitudes influencia o desempenho dos alunos. Se intimidados, pôem-se a estudar detalhes mínimos, sem a compreensāo do todo, esperando por uma prova do tipo armadilha; se tranquilizados, estudam apenas aqueles tópicos que foram revisados na última aula e também perdem a visão de conjunto sobre os conteúdos. De qualquer forma, a resoluçăo de tal prova por aqueles alunos já está viciada pela atitude do professor. 
Se uma prova é planejada em conjunto, por um grupo de professores que lecionam a mesma disciplina, há pelo menos duas possibilidades:

a) cada professor recebe o esquema da prova e recheia-o com as questóes a que seus alunos estão acostumados. Nesse caso, não está avaliando a compreensăo daquele conteúdo, mas a de um conhecimento particular, reduzido, objeto de sucessivas transposiçöes didáticas. ${ }^{4}$

b) todos os professores farão a mesma prova, no mesmo horário. Nesse caso, muitos alunos serão avaliados pelo seu desempenho em conteúdos que não foram trabalhados por eles. $\mathrm{Na}$ correção da prova, então, sabedor desse fato, o professor poderá ser, talvez, mais indulgente na correçẫo das questôes cujos conteúdos não foram por ele ensinados. Em qualquer caso, é um viés que se estabelece no processo.

O momento da aplicação da prova também tem, em geral, um ritual implícito, mais ou menos aceito por todos. O professor solicita um determinada disposição das classes, faz algumas admoestaçōes sobre possíveis colas, marca o tempo de duração da prova, passeia pela sala, como que fazendo a ronda do local ou senta-se em posição estratégica, controlando os alunos com os olhos.

Toda essa encenação tem o objetivo manifesto de impedir a cola, mas traz subjacente a idéia de que o conhecimento, transmitido aos alunos de uma determinada forma, deve ser reproduzido dessa única maneira considerada correta. Assim, o diálogo entre professor e aluno, que possa ter sido estimulado durante as aulas e que possa ter, efetivamente, levado o aluno a atingir uma melhor compreensão dos conteúdos, é bruscamente interrompido. A prova introduz, entăo, um desequilíbrio nas relaçōes entre o professor e os alunos em torno do saber.

Queremos esclarecer que năo somos contrários à elaboraçäo individual das soluçб̋es dos problemas propostos e que acreditamos ser essa, efetivamente, uma etapa importante no desenvolvimento do aluno. No entanto, ela deveria ser constante, deveria ocorrer em todas

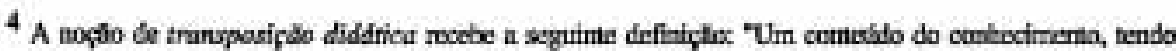

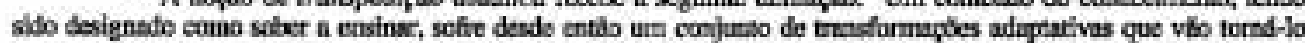

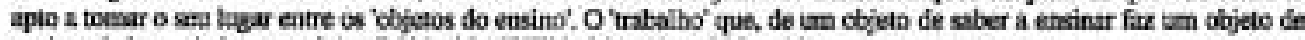

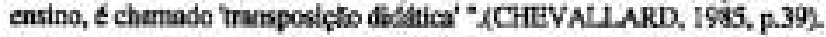


as aulas e nāo, apenas, em uma, duas ou três oportunidades, durante um semestre letivo. Em nosso entender, tal atitude fraciona o processo de aprendizagem, sem dúvida concebido como aquisiçăo de conteúdos delimitados. Năo $\mathfrak{e}$ por acaso que os alunos perguntam freqüentemente: "Até onde vai a matéria para a prova?"

Em Matemática, de modo geral, o professor, ao elaborar uma prova, faz, também, o gabarito, ou seja, o modelo segundo o qual o aluno deve resolver as questōes. Assim, a verdade do professor, a sua maneira de solucionar as questōes serve de modelo para a correçăo das provas dos alunos.

Parece-nos que a visão absolutista da Matemática está presente nesse procedimento dos professores: eles acreditam, efetivamente, na existência, em Matemática, de uma verdade absoluta que nāo pode ser sujeita a críticas e correçốes e, por extensão, de uma maneira de fazer, uma resolução certa que deveria ser seguida por todos.

Quando os professores de Matemática constroem um gabarito, já estāo estabelecendo uma verdade única, isolada da realidade dos alunos. Outro agravante pode ser citado: ao avaliar a prova separadamente das outras atividades desenvolvidas durante o período de aprendizagem, ou seja, do próprio trabalho de sala de aula, do estudo individual ou dos trabalhos de casa, o professor isola o processo de aprendizagem de seu produto.

$\mathrm{Na}$ correçāo de cada questão, surge, em nossa opiniăo, novamente o laivo absolutista, agora em sua versăo formalista, quando o professor considera que as regras formais de uso do conteúdo sāo mais importantes do que o significado que ê atribuído a esse conteúdo. E såo as regras que contam na avaliaçäo, uma vez que ela é feita com base no uso das mesmas regras em uma prova. Mesmo quando o professor salienta sua preocupaçắo com o desenvolvimento da questão, essa observação se refere ao encadeamento lógico dos raciocínios, à elegância, à correçāo, ao rigor das provas apresentadas, ou seja, àqueles elementos valorizados pela comunidade matemática, scgundo os quais um trabalho na área pode ou não habilitar-se a ser lido pelos membros dessa comunidade.

Năo estamos negando a importância desses elementos, efetivamente indispensáveis à apresentação de um conteúdo 
matemático. Não consideramos, também, a possibilidade de aceitar qualquer soluçảo como válida, apenas porque houve esforço do aluno em realizar a tarefa proposta ${ }^{5}$. Acreditamos, isso sim, que a avaliação, como vem sendo feita em geral, não leva em conta o processo de chegar à solução, nāo usa os erros dos alunos como subsídios para a compreensão dc suas dificuldades e, especialmente, năo parte dos erros para desafiar o aluno a mudar, a crescer no entendimento, a desenvolver sua capacidade de crítica, de análise e de generalização.

Outro aspecto que merece destaque, no processo de avalią̧äo em Matemática, em geral desenvolvido, é o hábito de corrigir cada prova separadamente, pois parece haver influência do pré-julgamento do professor sobre o aluno que realiza tal prova: se é um bom estudante, que mostra, em aula, domínio dos conteúdos, o professor tende a ser mais indulgente com os seus erros do que o será com os daquele aluno considerado ruim.

Também os erros cometidos na prova modificam o julgamento: se a maior parte deles está na resoluçāo das primeiras questōes, o professor poderá ser mais duro na correção das questōes restantes; se, por outro lado, as primeiras foram corretamente respondidas, o mestre poderá ser mais indulgente com os erros detectados ao final.

Há, ainda, o somatório das influências citadas: o aluno bom, que erra nas respostas das primeiras questōes, poderá ter esses erros neutralizados pelo pré-julgamento favorável do professor e o desempenho nas questões finais determinará sua avaliação. Se acerta as primeiras questőes, o pré-julgamento poderá ser reforçado e as questōes finais serāo corrigidas com menos rigor.

Se o aluno é ruim e erra nas primeiras questōes, esse fato, aliado ao pré-julgamento, poderá fazer com que os acertos porventura existentes na segunda parte sejam praticamente desconsiderados (o professor, para eximir-se de culpa, às vezes racionaliza dizendo: "deve ter colado essas últimas, para conseguir acertá-las") . Mesmo acertando as primeiras questóes, o desempenho do aluno poderá ser olhado com desconfiança e os erros, quando surgirem, funcionarão como uma

${ }^{5}$ Certas pasturas pechagógicas malo-diretivas proptem uma avaliaple que impede, em nosso entender, o

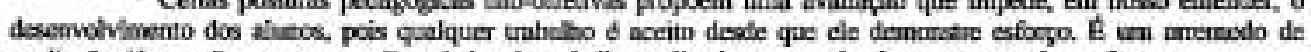

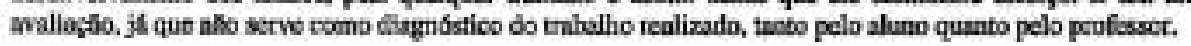


evidência, para o professor, da justeza de seu pré-julgamento. (Chevallard e Feldmann, 1986).

Os viéses acima discutidos podem ser minimizados se a correçăo das provas for realizada questäo por questão, como vários professores fazem. No entanto, tal procedimento não os elimina pois a comparação passa a ser feita, então, com as melhores soluçöes apresentadas para aquela determinada questāo.

$\mathrm{Na}$ correção da prova, o peso atribuído a cada questāo e os critérios para a correçăo (aceitar meia questão, neutralizar pontos negativos com positivos, etc.) partem do princípio de que o saber é passível de medição. Tal concepção, que remonta aos séculos XVIII e XIX, com a invasăo da Estatística e da Demografia nas Ciências Sociais (Chevallard e Feldmann, 1986), traz incoerências muito grandes, como a atribuição do zero. - O conhecimento nulo existe? - E se $o$ aluno entrega a prova em branco, o zero que the é atribuído mede a atitude de recusa a submeter-se a uma avaliaçăo que, de alguma forma, não corresponde ao esperado?

Qualquer que seja a nota atribufda ao aluno, o desequilibrio na relaçắo professor-aluno-conhecimento terá seus efcitos, tarnbém, no desempenho dos estudantes nas próximas avaliaçôes da mesma disciplina. A prova serve de ocasiăo de aprendizagem, uma vez que o aluno descobre, pelo tipo de questão proposta, quais os conteúdos matemáticos que devem ser aprendidos, qual o objeto de aprendizagem valorizado pelo professor e pela sociedade. Assim, a concepção de Matemática do professor é transmitida aos alunos.

A nota, publicada pelo professor e enviada à Administração, escamoteia, para o exterior, todas as experiências vividas em sala de aula: os debates, as tensōes, as frustraçőes e as alegrias do processo.

A nota final do semestre, sendo uma média (aritmética ou ponderada, conforme as regras estabelecidas), é ainda mais falível do que as parciais, pois dá uma impressão de desempenho homogêneo que o aluno, na maior parte das vezes, nåo teve no decorrer do semestre.

Em um curso universitário, com regime de disciplinas semestrais e pré-requisitos para matrícula, as notas em Matemática (em geral as mais baixas em cursos em que essa disciplina não é básica) têm, ainda, a funçāo de selecionar aqueles que poderão cursar disciplinas subseqüentes do currículo. Assim, a Matemática serve como filtro, selecionando os mais aptos, conforme a visão platônica. 
Parece-nos que há um aspecto desconsiderado, em geral, no processo de avaliação: a relação entre professores e alunos com vistas ao conhecimento. Os pesquisadores franceses, ligados aos IREM, têmse referido, freqüentemente, à noção de contrato didático, introduzida por Brousseau, a partir das idéias de Rousseau, expostas em $O$ contrato social.

Brousseau (1986) considera que a única maneira de fazer Matemática é buscando e resolvendo problemas específicos, e que o aluno, ao resolver os bons problemas propostos pelo professor, aprende o conteúdo em questão. Se o aluno não consegue resolvê-los, por um ou outro motivo, o professor tem a obrigação de ajudá-lo e, até, de justificar a escolha de um problema difícil ${ }^{6}$. A noção de contrato didático independe da concepção filosófica ou pedagógica assumida pelo professor, uma vez que é uma relaçăo que se estabelece toda a vez que um professor e seus alunos reúnem-se em torno de um conhecimento. Segundo o autor, essa relação

"...determina - explicitamente em parte, mas sobretudo implicitamente - o que cada parceiro, o professor e o aluno, tem a responsabilidade de gerar e do qual ele será, de uma maneira ou de outra, responsável perante o outro. Esse sistema de obrigaçöes reciprocas é semelhante a um contrato. $O$ que nos interessa aqui é o contrato didático, isto é, a parte desse contrato que é especifico do 'conteúdo': o conhecimento matemático visado." (BROUSSEAU, 1986, p.51).

O contrato didático reúne, portanto, três instâncias: 0 aluno, $O$ professor e o conhecimento. Não há a alternativa de aceitá-lo ou recusá-lo; o contrato está posto no momento em que os alunos e o professor se encontram em torno do conhecimento ensinado. "Os contratantes, eles mesmos, não pré-existem ao contrato. É o contrato que os cria."(CHEVALLARD, 1988, p.11).

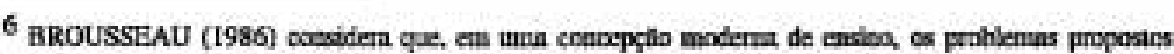

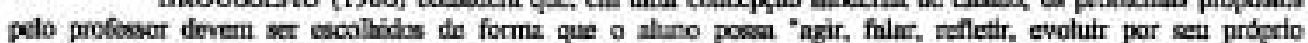
movimento" (p.49) e que o profossor nlo deve iniervir no sentiflo de apresentar cortedidn, a nlo ser que o aluno soliche, para a resolucilo do problema. 
As regras não săo enunciadas pois o contrato jamais será conclufdo, fechado. Ele está sempre em se fazendo. Fica tacitamente estabelecido que a situação de sala de aula é diferente de qualquer outra que professores e alunos vivenciam, e, de certa forma, o saber cotidiano é deixado em suspenso. Como diz Chevallard:

"...o contrato determina, tanto para o professor como para o aluno, uma Weltanschauung particular, visão de mundo didática além de outras visōes de mundo possiveis, e em várias maneiras, estranha à visão de mundo na qual evoluem ordinariamente os individuos fora da relaçāo didática." (CHEVALLARD, 1988, p.12).

Parece existir, na sala de aula, uma lógica própria, geradora das respostas dos alunos, de tal forma que o que já sabem, o saber cotidiano, é desprezado frente ao formal. O mesmo autor, evidenciando abertura em direçāo a uma nova visấo da Matemática e de seu ensino, reclama dessa postura:

"Que os alunos dispōem de duas 'ógicas', uma 'sagrada' (a do contrato didático), a outra 'profana', é verossímil. Que a primeira seja de qualquer maneira selecionada pelo ritual escolar e a outra abandonada à porta da sala de aula, parece plausível. Mas porque nāo haveria uma forma de solidariedade ou de casamento entre elas, a lógica profana colocando-se em movimento cada vez que o exercício normal da logica sagrada tornar-se impossivel (não pertinente) em conseqüência da ruptura, intencional ou näo, do contrato didático?" (Ibid., p.17).

Seria o caso de questionar se, em uma prova, por exemplo, não se poderia aceitar o conhecimento profano, informal, nåo sistematizado, mas que mostra como o aluno está-se desenvolvendo buscando atingir um patamar mais elevado de compreensão do conteúdo.

O papel do professor no processo de ensino-aprendizagem "encontra-se mediado pelo contrato didático, que fixa a exigência de 
uma progressāo no saber."(CHEVALLARD E FELDMANN, 1986, P.68). Há um conjunto de exigências que o professor (e a Instituição) consideram legitimas: o tempo dedicado a um determinado conteúdo, o tipo de questões propostas em provas, os critérios de correção. Tais elementos são negociados pelos alunos, aula por aula, em uma tentativa de baixar o nível de exigência ou, pelo menos, de adequá-lo às suas necessidades.

Cada contrato didático, portanto, tem uma história própria, pois cada turma tem a sua própria forma de progredir no conhecimento. Assim, não haveria, em princípio, a possibilidade de elaboração de uma prova padrāo para diferentes turmas de uma mesma disciplina.

CHEVALLARD e FELDMANN (1986, p.70) acreditam que a avaliação é "racional em suas intenções, mas irracional em seu funcionamento". A avaliaçăo é um "ritual de passagem", pois, enquanto os alunos se submetem às questōes propostas pelo professor, esse é submetido, pelas respostas dos alunos, a outra questão "igualmente cruel":

"A correção, longe de ser, para o professor, um momento como os outros do processo didático, vivido com igual serenidade, aparece como a prova por excelência, da qual se livra ou da qual, pelo contrário, faz una pequena crucificação que reaparece regularmente." (Ibid.,p.71).

O professor sente-se avaliado a cada prova que propöe aos alunos, pois o mau resultado apresentado pelos estudantes representa o fracasso do professor, como um dos contratantes.

A nota atribufda à prova é uma mensagem que tem como destinatárío não só o aluno, mas o mundo exterior: os pais, a Instituição e a sociedade. Mesmo que o professor nāo concorde com a nota por ele atribuída a um aluno - por considerar que esse sabe mais do que evidenciou na prova -, e faça um comentário sobre isso, oralmente ou na própria prova, indicando que conteúdos, no seu entender, o aluno deve retomar, estabelece-se um mal-estar entre ambos que atrapalha as próximas interações professor-aluno. 
A visão formalista da Maternática, aliada a uma abordagem tocnicista ${ }^{7}$ do processo de ensino-aprendizagem, faz-se sentir na avaliaçăo, desde o momento da elaboração das questōes, quando o professor parte da idéia de ajustá-las às supostas capacidades que o aluno deveria ter desenvolvido. "Nessa concepçäo, a tarefa do professor (...) torna-se uma simples atividade de calibragem efetuada por um operador - o professor - em relação a um objeto- os alunos."(CHEVALLARD e FELDMANN, 1986, p.74).

Retomando as consideraçōes até aqui apresentadas, acreditamos que a concepção absolutista da Matemática é a que mais influencia as práticas avaliativas, vigentes no ensino dessa disciplina. As idéias de Platão, Descartes e da escola formalista podem ser relacionadas com algumas das etapas do processo de avaliação.

A visão absolutista aparece, por exemplo, na elaboração das provas, quando são propostas questōes dissociadas da realidade dos alunos, como se a Matemática existisse em mundo à parte, e os alunos devessem raciocinar sobre os entes matemáticos "tais como se apresentam", conforme afirmava Platẫ.

Outra influência absolutista é a de Descartes, cujas regras para "bem conduzir a razão na busca da verdade" preconizavam o reducionismo:

"...dividir cada uma das dificuldades que eu havia de examinar em tantas parcelas quantas fosse possível e necessário para melhor as resolver(...) conduzir por ordem os meus pensamentos, começando pelos objetos mais simples $e$ mais fáceis de conhecer, para subir pouco a pouco, gradualmente, até ao conhecimento dos mais compostos. (DESCARTES, 1988, p.57).

Esse método analítico tornou-se uma característica do pensamento científico e está vivo e presente no ensino de Matemática. Considera-se que o aluno sabe resolver um problema, quando divide as dificuldades, examinando-as uma a uma, começando pelas partes

7 Fus aberdapen. segundo L.thineo (1985) e Saviani (1991), busca planejar a ednenglo segundo

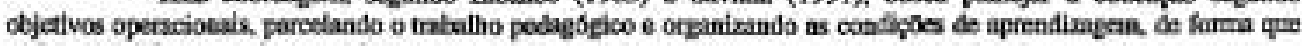
o mlano modifiquo sea desempentio. 
mais simples. Esse reducionismo, no entanto, é insustentável, se considerarmos o processo global, pois se perde a capacidade de ver o todo e as suas interrelações.

Ensinar a difícil tarefa de ver o todo, examiná-lo em suas partes e voltar ao todo com uma nova visão obtida a partir da análise das partes, deveria ser um dos objetivos da Matemática como disciplina de um currículo escolar, em qualquer nível. Não obstante, na maior parte das vezes, é enfatizada a reduçăo às partes, picoteandose os conteúdos programáticos e impedindo, por conseqüência, o aluno de ver o todo. Essa postura, em termos de avaliaçāo, reflete-se no momento em que há a preocupação de descontar pontos por cada erro cometido em uma resoluçāo, sem tentar entender o raciocínio global, o caminho pelo qual o aluno chegou àquele erro, a mensagem que ele passa sobre as suas dificuldades.

Pressupooe-se, também, ao corrigir as provas, que os alunos tenham justificado cada passo das demonstrações, em uma linguagem formal, simbolizada, livre de contradiçôes; nas questôes que envolvem algoritmos, espera-se que executem os cálculos na seqüência certa. Está-se, assim, aceitando uma postura formalista, do tipo: faz assimaplica essa definiçâo-demonstra dessa forma.

A preocupação com a eliminação dos erros cometidos pelos alunos, tão própria da concepção que vê a Matemática como o domínio do conhecimento absoluto $\mathrm{c}$ infalível, parte da idéia equivocada de que os textos matemáticos não têm erros. Davis (1972) comenta a existência de uma obra, publicada em 1935, na qual, em mais de 130 páginas, săo listados erros cometidos por matemáticos desde a antigüidade, arrolando, também, os autores que descobriram os erros e as discussōes por eles geradas.

A existência de erros cometidos por matemáticos não é, evidentemente, uma desculpa para aceitar trabalhos errados dos alunos; queremos, apenas, lembrar que a Matemática é corrigivel e que se desenvolve por meio das correções que a comunidade matemática vem fazendo ao longo dos séculos. Há, portanto, um papel fecundo atribuído aos erros, no desenvolvimento da Matemática. As geometrias näo-euclideanas, por exemplo, não teriam sido criadas, se não tivessem ocorrido fracassos nas tentativas de provar $05^{\circ}$ postulado de Euclides.

Pesquisa realizada com professores universitários de Matemática (Cury, 1994), mostrou que a maioria têm uma visāo 
absolutista da Matemática, considerando-a como o domínio das verdades absolutas, que se dispōem em uma estrutura complexa, onde imperam a ordem e o rigor. Mesmo quando apresentam mudanças em suas práticas, contestando certos aspectos do ensino tradicional, os professores estão imbuídos da idéia de que a Matemática é importante no desenvolvimento da essência do homem e de que devem evitar os caminhos que possam levar os alunos a erros.

Não há evidência, pelo menos entre os participantes da pesquisa, da aceitação da visão falibilista, que vê a Matemática como um campo em constante mudança, cujo conhecimento nasce da atividade humana, como parte de um processo social.

Mesmo aqueles professores que consideram estar a Matemática diretamente ligada às necessidades cotidianas, não parecem ver a possibilidade de o conhecimento matemático ser falível e corrigível. Esse conhecimento faz parte da vida diária e só tem sentido se for útil as necessidades cotidianas, mas é exato, indubitável e, uma vez estabelecido, deve ser ensinado como verdade absoluta.

A avaliaçāo realizada pela maioria dos participantes da pesquisa é a tradicional, em que sāo utilizados testes e provas escritas, esperando-se que o aluno reproduza o que foi ensinado. Na correçäo das provas, os professores, em geral, assinalam os erros cometidos, com o objetivo de conscientizar o aluno sobre suas ocorrências, para que possa eliminá-los em ouitra oportunidade.

Alguns respondentes declararam-se insatisfeitos com os procedimentos utilizados para a avaliaçăo, apesar de não saberem como fazer para modificá-los. Mas os erros cometidos pelos alunos podem ser um "trampolim para a investigaçăo", nas palavras de Borasi (1988). A autora exemplifica o potencial educacional dos erros no ensino da Matemática, mostrando diferentes definiçōes incorretas de circunferência, dadas por um grupo de alunos. Tomando cada uma delas, a autora sugere que os alunos tentem descobrir que outros entes matemáticos poderiam ser descritos a partir de cada definiçäo; quais as conseqüências por aceitar essas definições; quais as propriedades da circunferência que continuariam válidas; o que significa definir, em termos matemáticos.

As idéias de Borasi poderiam servir, portanto, como sugestão de mudança para os professores que, apesar de inconformados com o processo avaliativo por eles desenvolvido, não encontram formas de substitui-lo. 
Em uma perspectiva de ensino centrada no processo, aceitando a possibilidade de refutar e corrigir os conceitos matemáticos, poderse-ia partir dos erros para explorar a Matemática, desenvolvendo, assim, a capacidade crítica dos alunos, relacionando a visão falibilista da Matemática com o processo de avaliação da aprendizagem dessa disciplina e oferecendo novas perspectivas para o ensino de Matemática nos cursos universitários.

\section{REFERENCIAS BIBLIOGRÁFICAS}

BLAIRE, Eric. Philosophies of mathematics and perspectives of mathematics teaching. International Journal of Mathematical Education in Science and Technology, v.12, n.2, p.147-153, Mar./Apr. 1981.

BORASI, Raffaella. Beyond diagnosis and remediation. Budapest, 1988a. 6 p. Trabalho apresentado no $6^{\circ}$ ICMI, realizado em Budapest, Hungria, de 27 de julho a 3 de agosto de 1988.

BROUSSEAU, Guy. Fondements et méthodes de la didactique des mathématiques. Recherches en Didactique des Mathématiques, v.7, n.2, p.33-115, 1986.

CHEVALLARD, Yves. La Transposition didactique: du savoir savant au savoir enseigné. Grenoble: La Pensée Sauvage, 1985.

Sur l'analyse didactique. Marseille: IREM, 1988. (Publications de I'TREM d'Aix-Marseille, 14).

CHEVAllard, Yves, FEldMANN, Serge. Pour une analyse didactique de l'evaluation. Marseille: IREM, 1986. (Publications de l'IREM d'Aix-Marseille, 3).

CURY, Helena Noronha. As concepções de matemática dos professores e suas formas de considerar os erros dos alunos. Porto Alegre: UFRGS, 1994. Tese (Doutorado em Educação) Faculdade de Educação, Universidade Federal do Rio Grande do Sul.

DAVIS, Philip J. Fidelity in mathematical discourse: is one and one really two? American Mathematical Monthly, v.79, n.3, p.252263, Mar. 1972.

Applied mathematics as social contract. Mathematics Magazine, v.61, n.3, p.139-147, June 1988. 
DESCARTES, René. Discurso do método. Lisboa: Edições 70, 1988. ERNEST, Paul. The philosophy of mathematics and mathematics education. International Journal of Mathematical Education in Science and Technology, v.16, n.5, p.603-612, 1985. Philosophy, mathematics and education. International Journal of Mathematical Education in Science and Technology, v.20, n.4, p.555-559, July/Aug. 1989.

The impact of beliefs on the teaching of mathematics. In: ERNEST, Paul. (ed.). Mathematics teaching: the state of the art. 2. ed. London: Falmer, 1991 a. p.249-254.

The philosophy of mathematics education. London: Falmer, 1991 b.

KÖRNER, S. Uma introdução à filosofia da matemática. Rio de Janeiro: Zahar, 1985.

LERMAN, Stephen. Problem-solving or knowledge-centred: the influence of philosophy on mathematics teaching. International Journal of Mathematical Education in Science and Technology, v.14, n.1, p.59-66, Jan./Feb. 1983.

LIBÂNEO, José Carlos. Democratização da escola pública: a pedagogia crítico-social dos conteúdos. 2. ed. Săo Paulo: Loyola, 1985.

SAVIANI, Dermeval. Escola e democracia. 25. ed. São Paulo: Cortez, 1991.

TYMOCZKO, Thomas, Making room for mathematicians in the philosophy of mathematics. Mathematical Intelligencer, v.8, n.3, p.44-50, 1986.

UPINSKY, Arnaud-Aaron. A Perversão matemática. Rio de Janeiro: Francisco Alves, 1989. 